\title{
Effects of Output Quality and Result Demonstrability on the Perceived Usefulness of GPS Sports Watches from the Perspective of Industry 4.0
}

\author{
Ming-Zhu Yuan, ${ }^{1}$ Jan-Wei Lin, ${ }^{2}$ Cheng-Chia Yang, ${ }^{1}$ I-Chi Wang, ${ }^{3}$ and Chin-Hsien Hsu $\mathbb{I D}^{4}$ \\ ${ }^{1}$ Department of Healthcare Administration, Asia University, Taichung, Taiwan \\ ${ }^{2}$ Center for General Education Sports Administrative Organization, National Chi Nan University, Nantou County, Taiwan \\ ${ }^{3}$ Department of Industrial Education and Technology, National Changhua University of Education, Changhua City, Taiwan \\ ${ }^{4}$ Department of Leisure Industry Management, National Chin-Yi University of Technology, Taichung City, Taiwan
}

Correspondence should be addressed to Chin-Hsien Hsu; hsu6292000@yahoo.com.tw

Received 24 August 2021; Revised 22 October 2021; Accepted 5 November 2021; Published 20 November 2021

Academic Editor: Kuei-Hu Chang

Copyright (c) 2021 Ming-Zhu Yuan et al. This is an open access article distributed under the Creative Commons Attribution License, which permits unrestricted use, distribution, and reproduction in any medium, provided the original work is properly cited.

\begin{abstract}
In the wave of Industry 4.0, GPS sports watches are redeveloping towards digitization and intelligence. Whether the information is correct and real-time, operation interfaces easy to use and the displayed information easy to understand have become issues that consumers and manufacturers emphasize. Thus, this study investigated the effects of output quality and result demonstrability on the perceived usefulness of GPS sports watches with participants of the 2020 Taiwan International Triathlons as the research subjects. In total, 280 respondents, who participated in the 2020 Taiwan International Triathlon, were selected by purposive sampling for a questionnaire survey. The statistical software SPSS was employed to file the data, and the statistical software of AMOS was adopted to analyze the correlation among variables. According to the results, (1) output quality has significantly positive effects on perceived usefulness; (2) result demonstrability has significantly positive effects on perceived usefulness; (3) perceived ease of use has significantly positive effects on perceived usefulness; (4) perceived ease of use has significantly positive effects on behavioral intention to use; and (5) perceived usefulness has significantly positive effects on behavioral intention to use.
\end{abstract}

\section{Introduction}

With technological development and innovation, new business models and production modes have been emerging in global industries. The global manufacturing industry has moved towards service and intelligence, giving rise to the concept of Industry 4.0. According to [1], under the hightech strategy issued by the German government in 2011, Industry 4.0 (I4.0), or the Fourth Industrial Revolution, is jointly funded by the Federal Ministry of Education and Research and the Federal Ministry of Economy and Technology to promote the computerization, digitalization, and intelligence of the manufacturing industry. The goal of Industry 4.0 is not to create new industrial technologies. Instead, it integrates the technical information and business activity information related to the whole life cycle of the manufacturing industry to establish smart factories with high adaptability, high production elasticity, and high resource efficiency. Taiwan saw the global trend of smart manufacturing and proposed a "Productivity 4.0 Initiative" in 2015 to push the country's industry to the next stage. Wang and $\mathrm{Ma}$ [2] pointed out that the "Productivity 4.0 Initiative" promoted by Taiwan's Executive Yuan covers the agriculture and service industries in addition to the manufacturing industry. The main strategy involves making industries enter the stage of 4.0 by combining advantages of intelligent machinery and information communication in Taiwan and using technologies, such as the Internet of Things (IoT), intelligent robots, big data, and lean management. As mentioned above, Industry 4.0 not only focuses 
on creating new industrial technologies, but also emphasizes directly connecting with end-users or consumers by multiple intelligent methods. According to Ho [3], the primary difference of Industry 4.0 lies in the cyber-physical systems that integrate computing, communication, and control to connect various equipment systems in production by means of computers, sensors, and new-generation network techniques and achieve intelligent instant messaging and services with the ability of real-time perception and control through communication and interaction among them. The interaction between intelligent production and IoT will bring completely new changes to economic, political, and social environments.

Wearable sports devices are also being developed in such environments. Lin [4] emphasized that, with the advent of Industry 4.0, the concept of "quantified self" gradually seeps into people's daily lives, and they begin to record their body information through technology to pursue sports performance or stay healthy. Noteworthily, wearable devices are one of the key development projects of this trend. The survey and research data of Garnet [5] proved this view, showing that the global gross expenditure on wearable devices is forecasted to be US $\$ 81.5$ billion in 2021 , or $18.1 \%$ more than that in 2020. The COVID-19 pandemic is an important factor driving such market growth. In other words, mobile communication devices are mainstream today. Furthermore, according to Statist's prediction, global wrist wearable devices will increase from 70 million in 2019 to 110 million in 2023 [6].

According to the statistical data of Sports Administration, Ministry of Education, R.O.C. [7], in the 2019 sports status survey, nearly $80 \%$ of sports people most commonly do outdoor recreational sports, and $33.6 \%$ of the national population regularly participates in sports, hitting a record high with 20,000 people more than that in 2018. In other words, people have more opportunities to go outside for exercises, such as jogging, hiking, mountaineering, and canoeing. In terms of regular sports, the government and private agencies provide more spaces for people to do various indoor sports, which increase the opportunities to use GPS sports watches. The Sports Administration [7] echoed this development trend and pointed out that as Taiwan is experiencing a fitness craze, a new type of smart fitness that combines sports and technology has become a development trend. At the same time, various bureaucratic ministries are investing relevant resources. For instance, the Technology Department of the Ministry of Economic Affairs and the Institute for Information Industry set up the Sports Technology Alliance to serve enterprises, universities, and research institutes and promote the transformation and development of the sports industry.

People active in sports often use wearable devices, such as smart bracelets or watches, to understand their heartbeat, blood pressure, and other physiological information to provide a reference for personal trainers or themselves to develop sports regimens. Although GPS sports watches have become more mature today, people still face concerns about inaccurate and incomplete recorded data. For example, according to Shcherbina et al. [8], when heart rates and calorie expenditure are recorded by wrist wearable devices, the data of cycling are more accurate than that of walking; that is, the results do not have the same accuracy for different intensity and sports patterns. According to the results, when people record information by GPS sports watches, the accuracy and completeness of the recorded information are key indicators of product acceptance, indicating that GPS sports watch users focus on "output quality." In other words, "output quality" helps users understand the practicability of GPS sports watches and allows them to deliver results to others more clearly. For instance, the accurate tracking and physiological information recorded by GPS sports watches provides a reference for people to participate in the same activities, which corresponds to the meaning of GPS sports watches in exhibiting "result demonstrability."

According to the extended technology acceptance model proposed by Venkatesh and Davis [9], "output quality" and "result demonstrability" have effects of unperceived usefulness. People use GPS sports watches hoping that the data provided by such watches can record their own experience in sports and even improve the efficiency of self-training. Therefore, users naturally care about the accuracy of information recorded by GPS sports watches and the effects of GPS sports watches, both of which the extended technology acceptance model focuses on. The extended technology acceptance model can help understand people's behavior of adopting new technologies.

After a comprehensive review of the literature [10-12], it is found that most studies focus on the consumption behavior models of GPS sports watch consumers on wearable sports devices and how these devices improve consumers' sports performance rather than explore their behavior and experience of the new technology in wearable sports devices. Hence, this study intends to explore the experience of GPS sports watch consumers in using GPS sports watches to record their exercise process during sports. The extended TAM proposed by Venkatesh and Davis [9] shows the effects of "output quality" and "result demonstrability" on "perceived usefulness." It also helps understand people's behavior of adopting the new technology of wearable sports devices. Therefore, this study treated the participants of the Taitung International Triathlon as the research subjects and explored the effects of output quality and result demonstrability of GPS sports watches on the perceived usefulness from the perspective of Industry 4.0 by the extended TAM. Based on the results, suggestions are proposed for reference.

According to the literature review, while most studies on wearable sports devices focus on consumer behaviors $[10,13-15]$, some focus on sports performance $[11,12,16-19]$. However, there are only few studies on user experience. Therefore, this paper, with participants of a Taiwan international triathlon as the research subjects, explores the effects of output quality and result demonstrability of GPS sports watches on perceived usefulness from the perspective of Industry 4.0 via the extended technology acceptance model and makes suggestions at the end of the paper for reference. 


\section{Literature Review}

2.1. The Theory of Technology Acceptance Model. In early 1988, Davenport and Prusak [20] proposed that the evolution process of knowledge includes data, information, knowledge, and wisdom, where knowledge is collected and applied to take actions in the intelligent stage. This process indicates that while "data" show facts of the past, today's "wisdom" stage focuses on the ideas and decisions proposed in the future. With the intelligence of information technology and network techniques, the concept of Industry 4.0 helps enterprises develop systems that can predict human behaviors and habits and develop abilities to detect changes and make real-time decisions. According to Lee [21], Industry 4.0 was first proposed in Hannover Messed in 2011. In 2012, Germany's federal government, in a joint effort with German industries and research institutions, formed a workgroup of Industry 4.0, aiming to implement one of the ten plans of High-tech Strategy 2020 through this project. In recent years, countries have been fully aware of the advantages of Industry 4.0 and devoted their efforts to topics and technologies related to Industry 4.0. Hsiung [22] pointed out that improving national industrial competitiveness through the implementation of Industry 4.0 or smart manufacturing systems has become the core of many important national industrial policies in recent years. Hsu [23] agreed with this view and considered that smart manufacturing upgrading is the common goal of Industry 4.0 development in countries around the world. Bureaucratic units of the Taiwan government have paid attention to Industry 4.0 development in various countries. According to the Executive Yuan [24], in the past three years, the world's major countries have actively promoted the construction of cyber-physical intelligent manufacturing, production, and sales systems for rapid response or market demand prediction, such as Germany's "Industry 4.0," the United States' reindustrialization policy, Japan's man-machine coexistence future factory, South Korea's next-generation smart factory, or China's “Made in China 2025” plan. In 2016, the Taiwan government formulated the "Productivity 4.0 Initiative" to develop technologies, such as intelligent machines, IT, big data, and cloud computing, and improve the added values of products and services in manufacturing, commerce, services, and agriculture [23].

Wang and Chiang [1] considered that the Industry 4.0 technology concept includes cyber-physical systems (CPS), Internet of things (IoT), and Internet of service (IoS) and linked the design and development data, equipment, personnel, manufacturing process, and digital data in the production process. Equipment can perform independent monitoring, analysis, and judgment and conduct autonomous communication cooperation according to the production status to make the production process more flexible. Therefore, wearable devices continuously collect users' physiological information using the computing power of IoT by combining artificial intelligence technology with sensor applications to build effective databases and then providing users with more suggestions on sports through applications and comparative analysis.
With such technological progress, people have more opportunities to gain access to technological products than ever before. For various technological products, understanding consumers' behaviors and usage habits has become the focus of industries. Lee et al. [25] pointed out that, in theories of information technology equipment acceptance, the technology acceptance model (TAM), proposed by Davis in 1986, is the most widely used and can be applied to research with different people, information systems, and working places at different times. TAM was gradually developed from the theory of reasoned action (TRA). Proposed by Ajzen and Fishbein [26], TRA has been widely used in the last few decades in exploring and verifying individual behaviors. They argue that individuals' behavior, beliefs, and evaluations directly affect individual attitudes to certain behaviors. Further, attitudes and subjective norms will affect individual behavioral intentions, which are determinants directly affecting individual behaviors. Therefore, many factors affect individual acceptance of information technology, including attitudes, subjective norms, and perceived behavioral control. Through the technology acceptance model developed from the theory of reasoned action, Davis [27] concluded that perceived usefulness and perceived ease of use of information technology are two main determinants affecting behavioral intentions. Perceived usefulness means that users subjectively consider this technology to be helpful for job performance and the future. Meanwhile, perceived ease of use refers to the degree to which users perceive that the technology is easy to use. The easier the technology is to use, the more confident the users are in self-efficacy and selfcontrol, and the more positive their attitudes are towards systems. In this study, if people use GPS sports watches and find that the recorded data and provided information can help them improve their sports efficiency or training performance, their acceptance of GPS sports watches may be high. On the other hand, if the GPS sports watches provide users with intuitive and easy-to-use feelings in operation interface and data transmission, people may be more highly willing to use GPS sports watches.

\subsection{The Theory of Extension of the Technology Acceptance} Model. They may even be more confident, because GPS sports watches easily record information during sports activities. In addition, Davis [27] pointed out that perceived usefulness and perceived ease of use are also affected by external variables, such as personal traits, organizational structures, and task characteristics. They also emphasized that external variables can be regarded as indirect factors affecting behavioral intentions. In this study, people's attitudes towards GPS sports watches do not always remain the same, which varies with the changes of external factors. For example, ordinary people may only focus on recording sports time, mileage, or heart rates through GPS sports watches. However, professional athletes or mountain guides are more likely to force themselves to learn other advanced functions of GPS sports watches to help their professions or careers. After mastering the functions, they will be more willing to use GPS sports watches. As TAM has been applied 
in industries, its shortcomings have gradually appeared. According to Venkatesh and Davis [9], in many studies, TAM can only explain $40 \%$ of the variables in behavioral intention to use and usage behaviors and ignores factors, such as personal values, habits, and social influences. Thus, they proposed an extension of the technology acceptance model (TAM2) and considered that social influence processes and cognitive instrumental processes have certain effects on perceived usefulness. Social influence processes have three dimensions: subjective norm, voluntariness, and image. Meanwhile, cognitive instrumental processes have four dimensions: job relevance, output quality, result demonstrability, and perceived ease of use. Moderating variables include voluntariness and experience. Venkatesh and Davis further [9] explained these seven dimensions.

(1) Subject Norm: this dimension includes "internalization" and "identity" and affects perceived usefulness, indicating that important people affect the degree to which they use information systems

(2) Image: the degree to which users consider that using a new information technology system will enhance their social status

(3) Job Relevance: the degree to which users consider that their jobs can utilize an information system

(4) Output Quality: the degree to which users consider the good effects of an information system after fulfilling their task requirements

(5) Result Demonstrability: the result specificity that users consider after using an information system

(6) Experience: users' experience infusing an information system

(7) Voluntariness: the degree of active acceptance rather than passive acceptance in the process of using an information system

The above definitions show the effects of social influence processes and cognitive instrumental processes, thereby extending, explaining, and improving the explanatory ability of the theoretical model.

2.3. Hypothetico Deductive. For sports enthusiasts, GPS sports watches are in demand. According to Chen [28], the visual interface design of Apple Watches and ASUS's sports watches is better than Garmin's. Garmin reduces levels and is designed with low-resolution pixels to make the integral color and screen luminance more suitable for use in the sun to achieve low power consumption. People are more confident in the interface operation of Garmin, because the overall information architecture is simple and clear. In other words, GPS sports watch users have different requirements for result demonstrability and output quality of different brands of sports watches. According to the literature review, output quality has effects on perceived usefulness. The good effects of information systems in meeting task requirements make users subjectively consider that this technology is helpful for job performance and the future [29-31]. Thus, this paper proposes Hypothesis I: output quality has significant effects on perceived usefulness. Further, the significantly positive effects of result demonstrability on perceived usefulness are verified by some studies. After information systems are used, the result demonstrability makes users subjectively consider that this technology is helpful for job performance and the future [30, 32]. Thus, this paper proposes Hypothesis II: result demonstrability has significant effects on perceived usefulness. Some studies show that perceived ease of use has significantly positive effects on perceived usefulness. The easier users perceive the technology is to be used, the more confident they are in selfefficacy and self-control, and the more positive their attitudes are towards systems, making them subjectively consider that this technology is helpful for job performance and the future $[33,34]$. Thus, this study proposes Hypothesis III: perceived ease of use has significant effects on perceived usefulness. On the other hand, some studies support that perceived ease of use has significantly positive effects on behavioral intention to use. The easier users perceive the technology is to be used, the more confident they are in selfefficacy and self-control, and the more positive their attitudes are towards systems, thus affecting their intention to use this technology [35-37]. Still, other studies argue that perceived usefulness has significantly positive effects on behavioral intention to use $[25,38-40]$.

\section{Research Method}

3.1. Research Framework. This study aims to explore the effects of output quality and result demonstrability on the perceived usefulness of GPS sport swatches from the perspective of Industry 4.0. The research architecture proposed based on the research purposes and literature is shown in Figure 1.

3.2. Research Respondents. With 2020 Taiwan International Triathlons participants as the research respondents, this study has a sampling error of no more than $4.5 \%$ and a confidence interval of $95 \%$. The present study set the sample number as 280 and conducted a random sampling outside the 2020 Taiwan International Triathlons from November 14 th to November 15th, 2020. A total of 270 valid questionnaires were obtained after the questionnaires were returned, and the invalid ones were omitted, attaining a valid response rate of $92 \%$.

3.3. Research Instruments. The questionnaire of this study, developed based on the study and questionnaire of Guo (2013), consists of three parts with 23 items, including 9 on basic personal information, 10 on TAM, and 4 on cognitive promotion. A five-point Likert scale is used in this study, and each item is scored from 1 (strongly disagree) to 5 (strongly agree).

3.4. Data Processing and Analysis. In this study, the valid questionnaires are counted, while invalid questionnaires are removed. The statistical software SPSS 23.0 is used to create 


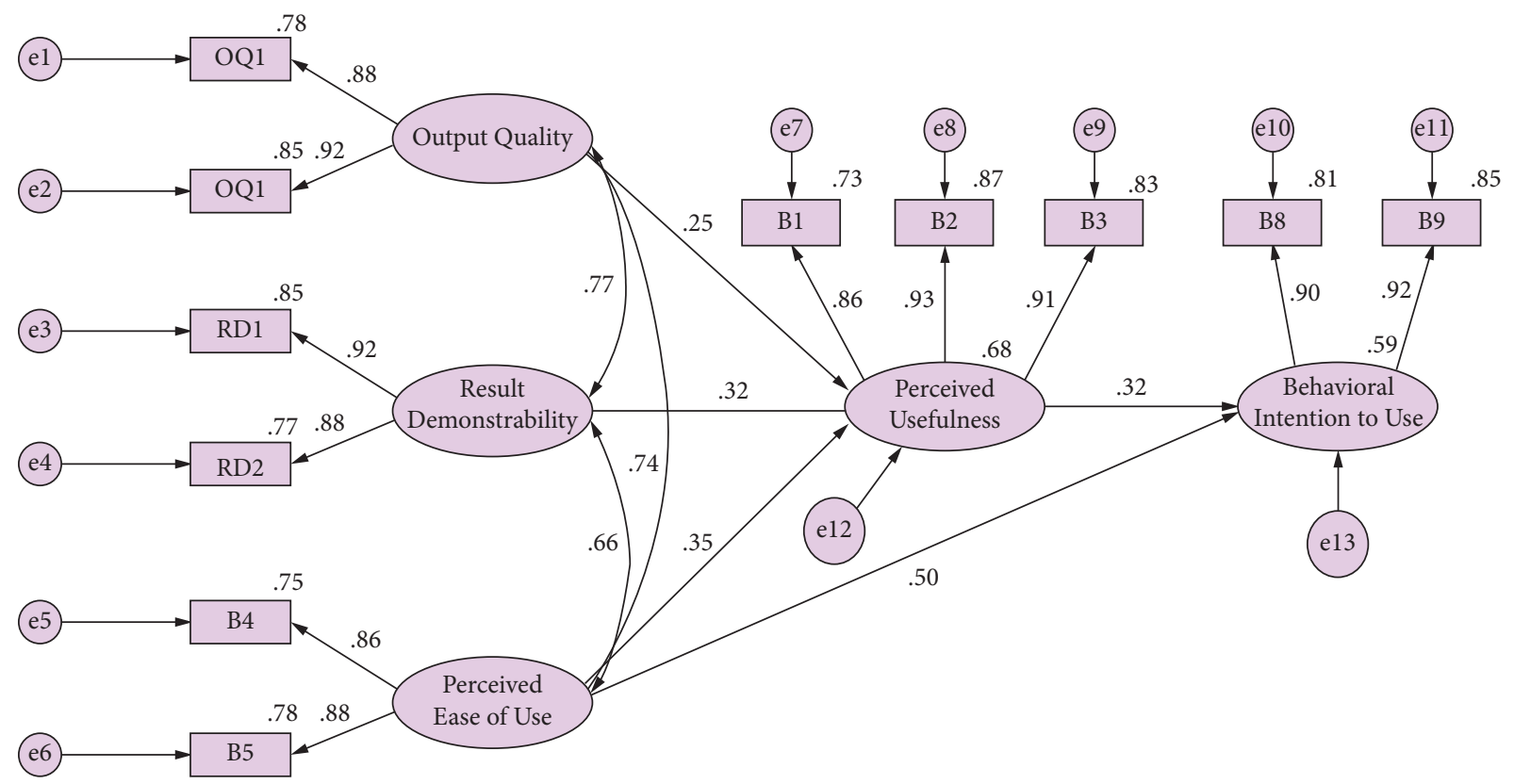

FIGURE 1: Effects of output quality and result demonstrability on the perceived usefulness of GPS sports watches from the perspective of industry 4.0 .

files based on the data, and the demographic variables are analyzed through descriptive statistics. On the other hand, the statistical software AMOS 23.0 is used for path analysis of the correlation among variables.

\section{Research Results}

4.1. Sample Characteristics. In this study, the participants of the Taitung international triathlon are taken as test samples with a total of 250 valid samples. In terms of gender, there are 184 males, accounting for $73.6 \%$ of the valid samples, and there are 66 females, accounting for $26.4 \%$. In terms of age, 99 people are between 30 and 39 , accounting for $39.6 \%$ of the valid samples, and 6 people are less than 19 years old, accounting for $2.4 \%$. In terms of the "participant" category, 117 respondents took part in the half triathlon, accounting for $46.8 \%$ of the valid samples. Meanwhile, 26 people participated in the "others" category, accounting for $10.4 \%$ of the valid samples. In terms of occupation, 92 respondents were students, which comprise the majority of the samples, accounting for $36.8 \%$ of the valid samples. On the other hand, 10 respondents were teachers, being the least, accounting for $4.0 \%$ of the valid samples. In terms of the educational level, 150 people have university (college) degree, accounting for $60 \%$ of the valid samples, and 19 people are below the senior high (higher vocational) school level, accounting for $7.6 \%$. In terms of income, 130 people earn more than NT $\$ 50,001$ per month, accounting for $52.0 \%$ of the valid samples, and 23 people earn more than NT\$20,001 and less than NT $\$ 30,000$ per month, accounting for $9.2 \%$. In terms of the number of competitions participated, 121 people have taken part in two to five competitions, accounting for $48.4 \%$ of the valid samples, and 28 people have taken part in more than 11 competitions, accounting for $11.2 \%$. In terms of training hours, 92 people train irregularly, accounting for $36.8 \%$ of the valid samples, and 5 people train over 21 hours per week, accounting for $2.0 \%$. In terms of sports seniority before purchasing GPS sports watches, 83 people have been exercising for four to five years, accounting for $33.2 \%$ of the valid samples, and 48 people have been exercising in less than one year, accounting for $19.2 \%$. Table 1 lists the samples' characteristics.

4.2. Measurement Model Analysis. In this study, the reliability and validity of the questionnaire are verified by Catalysis, items are corrected based on the modification indices (M.I.), and items B6, B7, and B10 of the TAM scale are deleted.

4.2.1. Verification of Convergent Validity. Bagozzi and Yi [41] pointed out that convergent validity verification mainly verifies the composite reliability (C.R.) and the average variance extracted (AVE) of questionnaire dimensions. They suggested that C.R. and AVE should be greater than 0.6 and 0.5 , respectively, to achieve good convergent validity [42]. In this study, the convergent validity of perceived usefulness and perceived ease of use is verified from the dimensions of behavioral intention to use, output quality, and result demonstrability. The verification results show that the factor loadings of all dimensions are between 0.78 and 0.93, C.R. is between 0.87 and 0.91 , and AVE is between 0.77 and 0.82 , satisfying the convergent validity criteria recommended by [41-43]. This indicates that the questionnaire in this study has good convergent validity, as shown in Tables 2-4.

4.2.2. Discriminate Validity. In this study, the discriminate validity is verified by the confidence interval method (bootstrap). This study first establishes the confidence 
TABLE 1: Tester characteristics.

\begin{tabular}{|c|c|c|c|c|}
\hline Variables & Categories & $\begin{array}{c}\text { Tester } \\
\text { characteristics }\end{array}$ & $\begin{array}{l}\text { Percentage } \\
\quad(\%)\end{array}$ & $\begin{array}{c}\text { Cumulative } \\
\text { percentage } \\
(\%)\end{array}$ \\
\hline \multirow{2}{*}{ Gender } & Male & 184 & 73.6 & 73.6 \\
\hline & Female & 66 & 26.4 & 100.0 \\
\hline \multirow{5}{*}{ Age } & Under 19 years old & 6 & 2.4 & 2.4 \\
\hline & $20-29$ years old & 48 & 19.2 & 21.6 \\
\hline & $30-39$ years old & 99 & 39.6 & 61.2 \\
\hline & 40-49 years old & 77 & 30.8 & 92.0 \\
\hline & Above 50 years old & 20 & 8.0 & 100.0 \\
\hline \multirow{4}{*}{ Participant category } & Half triathlon & 117 & 46.8 & 46.8 \\
\hline & Full triathlon & 45 & 18.0 & 64.8 \\
\hline & Standard triathlon & 62 & 24.8 & 89.6 \\
\hline & Others & 26 & 10.4 & 100.0 \\
\hline \multirow{6}{*}{ Occupation } & Military personnel & 13 & 5.2 & 5.2 \\
\hline & Civil servants & 19 & 7.6 & 12.8 \\
\hline & Teachers & 10 & 4.0 & 16.8 \\
\hline & Businessmen & 85 & 34.0 & 50.8 \\
\hline & Farmers & 31 & 12.4 & 63.2 \\
\hline & Students & 92 & 36.8 & 100.0 \\
\hline \multirow{3}{*}{ Educational level } & $\begin{array}{l}\text { Below senior high (higher vocational) } \\
\text { school level }\end{array}$ & 19 & 7.6 & 7.6 \\
\hline & University (college) degree & 150 & 60.0 & 67.6 \\
\hline & Above graduate school level & 81 & 32.4 & 100.0 \\
\hline \multirow{5}{*}{ Monthly income } & Less than NTD 20,000 & 32 & 12.8 & 12.8 \\
\hline & NTD $20,001-30,000$ & 23 & 9.2 & 22.0 \\
\hline & NTD $30,001-40,000$ & 35 & 14.0 & 36.0 \\
\hline & NTD 40,001-50,000 & 30 & 12.0 & 48.0 \\
\hline & More than NTD 50,001 & 130 & 52.0 & 100.0 \\
\hline \multirow{4}{*}{ Number of participations } & Once & 71 & 28.4 & 28.4 \\
\hline & $2-5$ times & 121 & 48.4 & 76.8 \\
\hline & 6-10 times & 30 & 12.0 & 88.8 \\
\hline & More than 11 times & 28 & 11.2 & 100.0 \\
\hline \multirow{5}{*}{ Training hours } & Irregular sports & 92 & 36.8 & 36.8 \\
\hline & Less than 6 hours per week & 51 & 20.4 & 57.2 \\
\hline & 7-12 hours per week & 77 & 30.8 & 88.0 \\
\hline & 13-20 hours per week & 25 & 10.0 & 98.0 \\
\hline & More than 21 hours per week & 5 & 2.0 & 100.0 \\
\hline \multirow{4}{*}{$\begin{array}{l}\text { Sports seniority before the purchase of GPS } \\
\text { sports watches }\end{array}$} & Less than 1 year & 48 & 19.2 & 19.2 \\
\hline & $2-3$ years & 70 & 28.0 & 47.2 \\
\hline & 4-5 years & 83 & 33.2 & 80.4 \\
\hline & More than 6 years & 49 & 19.6 & 100.0 \\
\hline
\end{tabular}

TABLE 2: Technology acceptance model confirmatory factor analysis.

\begin{tabular}{|c|c|c|c|c|c|c|c|c|c|}
\hline Dimensions & Indices & Standardized loadings & Nonstandardized loadings & S.E. & C.R. ( $t$-value $)$ & $P$ & SMC & C.R. & Ave \\
\hline \multirow{3}{*}{ Perceived usefulness } & B1 & 0.78 & 1.00 & & & & 0.60 & \multirow{3}{*}{0.91} & \multirow{3}{*}{0.77} \\
\hline & B2 & 0.93 & 1.11 & 0.07 & 16.76 & $* * *$ & 0.87 & & \\
\hline & B3 & 0.92 & 1.05 & 0.07 & 16.00 & $* * *$ & 0.85 & & \\
\hline \multirow{2}{*}{ Perceived ease of use } & B4 & 0.86 & 1.00 & & & & 0.73 & \multirow{2}{*}{0.87} & \multirow{2}{*}{0.77} \\
\hline & B5 & 0.90 & 1.07 & 0.07 & 15.81 & $* * *$ & 0.81 & & \\
\hline \multirow{2}{*}{ Behavioral intention to use } & B8 & 0.90 & 1.00 & & & & 0.81 & \multirow{2}{*}{0.90} & \multirow{2}{*}{0.82} \\
\hline & B9 & 0.92 & 1.03 & 0.06 & 18.09 & $* * *$ & 0.85 & & \\
\hline
\end{tabular}

${ }^{*} P<0.05,{ }^{* *} P<0.01,{ }^{* * *} P<0.001$.

interval for Pearson's correlation coefficient among dimensions and then tests whether it contains 1 to determine if the dimensions are completely correlated. According to the results, the confidence interval among dimensions does not contain 1 , indicating discriminate validity among dimensions in this study [44], as shown in Tables 5 and 6. 
TABLE 3: Output quality confirmatory factor analysis.

\begin{tabular}{|c|c|c|c|c|c|c|c|c|c|}
\hline Dimensions & Indices & Standardized loadings & Nonstandardized loadings & S.E. & C.R. ( $t$-value) & $P$ & SMC & C.R. & Ave \\
\hline \multirow{2}{*}{ Output quality } & OQ1 & 0.85 & 1.00 & & & & 0.72 & 0.88 & 0.79 \\
\hline & OQ2 & 0.93 & 1.03 & 0.06 & 17.89 & $* * *$ & 0.86 & & \\
\hline
\end{tabular}

TABLE 4: Result demonstrability confirmatory factor analysis.

\begin{tabular}{|c|c|c|c|c|c|c|c|c|c|}
\hline Dimensions & Indices & Standardized loadings & Nonstandardized loadings & S.E. & C.R. ( $t$-value $)$ & $P$ & SMC & C.R. & Ave \\
\hline \multirow{2}{*}{ Result demonstrability } & $\mathrm{RD} 1$ & 0.90 & 1.00 & & & & 0.82 & 0.89 & 0.81 \\
\hline & RD2 & 0.90 & 0.99 & 0.05 & 19.74 & $* * *$ & 0.81 & & \\
\hline
\end{tabular}

${ }^{*} P<0.05,{ }^{* *} P<0.01,{ }^{* * *} P<0.001$.

TABLe 5: 95\% confidence interval for bootstrap correlation coefficient of the technology acceptance model.

\begin{tabular}{|c|c|c|c|c|c|c|c|}
\hline & \multirow{2}{*}{\multicolumn{2}{|c|}{ Parameters }} & \multirow{2}{*}{ Estimates } & \multicolumn{2}{|c|}{ Bias-corrected } & \multicolumn{2}{|c|}{ Percentile method } \\
\hline & & & & Lower bound & Upper bound & Lower bound & Upper bound \\
\hline Perceived usefulness & $<-->$ & Perceived ease of use & 0.74 & 0.62 & 0.85 & 0.61 & 0.84 \\
\hline Perceived usefulness & $<-->$ & Behavioral intention to use & 0.68 & 0.54 & 0.79 & 0.54 & 0.79 \\
\hline Perceived ease of use & $<-->$ & Behavioral intention to use & 0.71 & 0.58 & 0.83 & 0.57 & 0.82 \\
\hline
\end{tabular}

Source: Compiled by this study.

TABLE 6: 95\% confidence interval for bootstrap correlation coefficient of the Output Quality model.

\begin{tabular}{llcccccc}
\hline & \multirow{2}{*}{ Parameters } & \multirow{2}{*}{ Estimates } & \multicolumn{2}{c}{ Bias-corrected } & \multicolumn{2}{c}{ Percentile method } \\
& & & Lower bound & Upper bound & Lower bound & Upper bound \\
\hline Output quality & $<->$ & Result demonstrability & 0.77 & 0.58 & 0.91 & 0.60 & 0.92 \\
\hline
\end{tabular}

Source: Compiled by this study.

4.2.3. Structural Model Analysis. According to the standards recommended by Hair et al. [43] in the structural model analysis, this study tests the overall model fit by 7 indices: chi-square value $\left(\chi^{2}\right)$, the ratio of $\chi^{2}$ to degrees of freedom, GFI, AGFI, RMSEA, CFI, and PCFI. The corrected ratio of $\chi^{2}$ to degrees of freedom is 1.94, which is consistent with the suggestion of Bagozzi and $\mathrm{Yi}$ [41] that the ratio of $\chi^{2}$ to degrees of freedom should be as small as possible. Hair et al. [43] described that GFI and AGFI should be as close as possible to 1 , respectively, 0.95 and 0.91 after correction in this study. The corrected RMSEA in this study is 0.06 , which conforms to the suggestion of Browne and Cudeck [45] that RMSEA should be less than 0.08. While the standard CFI should be larger than 0.90 , the corrected CFI in this study is 0.99 . On the other hand, while PCFI should be at least larger than 0.50 , the corrected PCFI in this study is 0.65 , which meets the recommended standard [46, 47]. Such results indicate that the overall fit indices are within the acceptable range and that the model is acceptable, as shown in Table 7.

Empirical results of research hypotheses.

4.3. Results. At the end of this study, the results of statistical analysis are compared with those of previous literature, and the results of hypothesis verification are discussed below. As shown in Table 7 , output quality has significantly positive effects on perceived usefulness, result demonstrability has significantly positive effects on perceived usefulness, perceived ease of use has significantly positive effects on perceived usefulness, perceived ease of use has significantly positive effects on behavioral intention to use, and perceived usefulness has significantly positive effects on behavioral intention to use.

4.4. Discuss. According to Table $8, \mathrm{H} 1$ is true-that is, output quality has significantly positive effects on perceived usefulness. This result is the same as that of Lee et al. [29], possibly because triathlon athletes believe that GPS sports watches can provide correct data and information and consider GPS sports watches to be helpful for training and competition. Further, $\mathrm{H} 2$ is also true-that is, result demonstrability has significantly positive effects on perceived usefulness. This conclusion is similar to that of Chang [32], possibly because the data provided by GPS sports watches make it easier for triathlon athletes to record their performance or adjust their training plans; hence, GPS sports watches are found to be helpful. On the other hand, H3 is true-that is, perceived ease of use has significantly positive effects on perceived usefulness. This result is similar to that of Lu and Lo [34], possibly because triathlon athletes have positive attitudes towards GPS sports watches if their training results improve feruling. Meanwhile, $\mathrm{H} 4$ is also true-that is, perceived ease of use has significantly positive 
TABLE 7: Overall model fit analysis.

\begin{tabular}{lccc}
\hline Fit indices & Permissible range & Correction model & Model fit discrimination \\
\hline$\chi^{2}$ (chi-square) & As small as possible & 69.9 & Passed \\
Ratio of $\chi^{2}$ to degree of freedom & $<3$ & 1.94 & Passed \\
GFI & $>0.80$ & 0.95 & Passed \\
AGFI & $>0.80$ & 0.91 & Passed \\
RMSEA & $<0.08$ & 0.06 & Passed \\
CFI & $>0.90$ & 0.99 & Passed \\
PCFI & $>0.50$ & 0.65 & \\
\hline
\end{tabular}

TABLe 8: Empirical results of research hypotheses.

\begin{tabular}{lccc}
\hline Hypotheses & Path relationship & Path value & Validity of hypotheses \\
\hline 1 & Output quality $\longrightarrow$ perceived usefulness & 0.25 & Valid \\
2 & Result demonstrability $\longrightarrow$ perceived usefulness & 0.32 & Valid \\
3 & Perceived ease of use $\longrightarrow$ perceived usefulness & 0.35 & Valid \\
4 & Perceived ease of use $\longrightarrow$ behavioral intention to use & 0.50 & Valid \\
5 & Perceived usefulness $\longrightarrow$ behavioral intention to use & 0.32 & Valid \\
\hline
\end{tabular}

effects on behavioral intention to use. This result is similar to that of Malik and Annuar [35], possibly because triathlon athletes are more willing to use GPS sports watches due to their effects on competition and training results. Lastly, $\mathrm{H} 5$ is true-that is, perceived usefulness has significantly positive effects on behavioral intention to use. This conclusion is similar to that of Ünal and Uzun [39], possibly because triathlon athletes believe that GPS sports watches are helpful to them and are more confident in such devices.

\section{Conclusion and Suggestions}

\subsection{Suggestions}

5.1.1. For Triathlon Participants. According to the results, output quality has significantly positive effects on perceived usefulness. With the advent of Industry 4.0 intelligent manufacturing, intelligent products have the advantages of information and communication by combining with big data. Therefore, it is suggested that triathlon participants first confirm the correct settings of their GPS sports watches to get the correct output quality. For example, in measurement settings, correct units, such as meter or feet, should be chosen to conform to the custom in the user area, or hap, mbar, or $\mathrm{mmHg}$ should be set first as the unit of air pressure. In addition, missteps sports watches have built-in orientation, altitude, and air pressure sensors-that is, ABC sports watches contain altimeters, barometers, and compasses. Therefore, before triathlon training or competition, it is necessary to clearly understand the principle of sensor calibration and calibrate sensors in advance. Because this is important to output quality, error settings, failure to calibrate, or after-event incorrect training and competition information may reduce the efficacy of GPS sports watches or the willingness to use them. Therefore, it is suggested that triathlon participants frequently or regularly correct GPS errors at the height of their current positions. For example, height information can be obtained through maps and local height indicators and then be manually input for correction to reduce the differences between the values obtained by GPS sports watches and the local elevations. Thus, the data obtained can be used as an ineffective reference for training and competition.

According to the results of this study, perceived usefulness also has significantly positive effects on behavioral intention to use. Hence, it is suggested that triathlon participants have a deep understanding of the correct use of GPS sports watches to improve their sports and training results effectively. For example, the data measured by optical heart rate monitoring devices are significant for triathlon participants since heart rate zones help determine training intensity. Thus, triathlon participants are suggested to avoid wearing such devices over their wrists to prevent inaccurate values caused by loose space between skin and optical heart rate meters. In addition, before training or competition, it is suggested to warm up to promote blood circulation, which will help GPS sports watches read heart rates more accurately and properly play their roles.

The results also show that result demonstrability has significantly positive effects on perceived usefulness. Hence, it is suggested that triathlon participants improve their abilities to understand technological information to make the results collected by GPS sports watches easy to observe and use. For example, in terms of technological resources of GPS sports watches (such as software and hardware supporting GPS sports watches, extended devices, and social media applications), if people are familiar with innovative information technologies, such as Strata or Relive APP, GPS sports watches can become training partners and improve personal training results.

5.1.2. For GPS Sports Watch Research and Development Manufacturers. According to the empirical results, perceived ease of use has significantly positive effects on perceived usefulness. Hence, under the future development 
trend of Industry4.0, it is suggested that GPS sports watch research and development manufacturers design hardware and software according to ergonomic standards to achieve a logical and human-based operation process of GPS sports watches. In addition, simple product interfaces and operations should be developed to make it easy for triathlon participants to use the devices and focus on training and competition. Furthermore, Industry 4.0 is the future trend for combining big data analysis and cloud computing to bring people into a smart life. In particular, social networks are flourishing, and "sharing" makes sports more interesting. Therefore, GPS sports watch research and development manufacturers should enable users to easily upload or share information through the simplest operations. For example, by combining GPS sports watches with sports APPs, training routes and tracks can be drawn and used with photos and text to contribute to triathlon networks. In addition, some triathlon participants can cross-train physically through other sports, such as cross-country running and mountaineering. Therefore, when GPS sports watches are combined with offline maps or built-in Taiwan hiking route maps, they can enable triathlon participants to know their locations even without the Internet or be integrated with others' tracks to serve as a reference. These designs can be considered good tools in diversifying training. In other words, if GPS sports watches are easy to use, they will be useful tools for triathlon participants to obtain the correct information and appropriate assistance.

According to the results, perceived ease of use has significantly positive effects on behavioral intention to use. Therefore, it is suggested that, in addition to designing easyto-operate interfaces, GPS sports watch research and development manufacturers consider classifying GPS sports watches as functional watches. Users with fixed exercise habits should also emphasize sport straining records and analysis. Considering that this is a niche market, the consumer base is not as wide as that of smart bracelets. Therefore, if GPS sports watch research and development manufacturers can make innovations in watch functions and make good use of online sports communities to retain users, the stickiness of GPS sports watch users can be improved, and their willingness to continue to use these devices can be enhanced.

5.1.3. For Future Studies. With triathlon participants as the research subjects, this paper conducts empirical research based on the theory of the extended technology acceptance model and explores the practical use of GPS sports watches and future research and development directions. However, through a comprehensive view of the current GPS sports watch market, it is important that products be highly recognized by consumers, offer assistance for users in sports, and produce different values. At present, the GPS sports watch market seems to have achieved the goal of having its products perceived as a matter of wants. However, there is still room for improvement before users could perceive it as a need. Therefore, closeness to users' living habits and bringing new values can effectively improve product stickiness. The construction of value focuses on users' intrinsic motivation to pursue happiness and fun, rather than the extrinsic motivation emphasized for perceived usefulness and ease of use in the past. Therefore, it is suggested that the third-generation technology acceptance model be used for future empirical studies.

In addition to the two variables of the extended TAM, namely, social influence process and cognitive instrumental process, "positioning" and "system adaptability" are incorporated into the third-generation TAM, including perceived enjoyment classified into system adaptability. Under the future development of Industry 4.0, creating fun at using GPS sports watches, making them entertaining, keeping users curious, and stimulating strong internal motivation will help enterprises understand the development trend of these products and the usage habits of future consumers.

\subsection{Research Limitations}

(1) In this study, a questionnaire survey is conducted among the 2020 Taitung International Triathlon participants by purposive sampling. Thus, the integrity of sample representativeness is limited.

(2) In the extended TAM theory, experience is also an interfering variable affecting perceived usefulness. Most respondents in this study do not have rich experience in GPS sports watches, making it difficult to determine the interference of experience unperceived usefulness.

(3) Research contributions: this study employed an extended technology acceptance model to explain the effects of "output quality" and "result demonstrability" on "perceived usefulness" and explored the behavior and experience of wearable sports devices that adopt new technologies. According to this study, product adhesion can be effectively improved by staying close to users' living habits and bringing new values. The "value" construction can skip past extrinsic motivation that emphasizes perceived usefulness and perceived ease of use and focus instead on the intrinsic motivation of users for happiness and fun. Therefore, the third-generation technology acceptance model can be used in future empirical studies. In addition to the two variables of social influence process and cognitive instrumental process of the extended technology acceptance model, an additional two variables, "positioning" and "system adaptability," were added to the third-generation technology acceptance model. Perceived enjoyment was classified into system adaptability to strengthen the integrity of the technology acceptance model, further explain the extension, and improve the explanatory ability of the theoretical model in order to understand users' behavioral intention of information technology.

5.3. Conclusion. As wearable devices become more mature, consumer demands for functions and efficiency have changed, encouraging manufacturers to constantly make 
innovations. In the wave of Industry 4.0, GPS sports watches certainly will develop towards digitization and intelligence. Whether the information is correct and real-time, operation interfaces easy to use and the displayed information easy to understand have become issues that consumers and manufacturers emphasize, showing the important role the GPS sports watches play in output quality in the future. Therefore, from the perspective of Industry 4.0, this study investigates the effects of output quality and result demonstrability of GPS sports watches on perceived usefulness.

\section{Data Availability}

The data are available upon request to the authors. The data source is obtained from the questionnaire analysis of the author's research.

\section{Conflicts of Interest}

The authors declare that they have no conflicts of interest.

\section{References}

[1] Y. C. Wang and T. H. Chiang, "Information management software technology for asset digitalization in industrial 4.0 application," Journal of the Techtronic Industry, vol. 437, pp. 23-31, 2019.

[2] C. N. Wang and Y. L. Ma, "International development trend of industry 4.0 and Taiwan's response measures," International Financial Reference Data, vol. 69, pp. 133-155, 2016.

[3] F. S. Ho, Industry Model and Influence of Industry 4.0, p. 454, Far Eastern Magazine, Taipei, Taiwan, 2015.

[4] K. F. Lin, "A study on Taiwan's runners purchase motivation of wearable device," Master's thesis, Department of Physical Education, National Taiwan Normal University, Taipei, Taiwan, 2017.

[5] Garnet, "Gartner forecasts global spending on wearable devices to total $\$ 81.5$ billion in 2021," 2021, https://www.gartner. com/en/newsroom/press-releases/2021-01-11-gartner-foreca sts-global-spending-on-wearable-devices-to-total-81-5-billi on-in-2021.

[6] P. H. Chen, Amazon's Intelligent Health Layout Fromthe Smart BraceletHalo, Market Intelligence \& Consulting Institute, Institute for Information Industry, Taipei, Taiwan, 2021.

[7] Sports Administration, “2020 sports statistics," 2020, https:// www.sa.gov.tw/Resource/Ebook/637499473534004656.pdf.

[8] A. Shcherbina, C. M. Mattsson, D. Waggott et al., "Accuracy in wrist-worn, sensor-based measurements of heart rate and energy expenditure in a diverse cohort," Journal of Personalized Medicine, vol. 7, no. 2, pp. 1-12, 2017.

[9] V. Venkatesh and F. D. Davis, "A theoretical extension of the technology acceptance model: four longitudinal field studies," Management Science, vol. 46, no. 2, pp. 186-204, 2000.

[10] C. Schultze and S. Burr, "Market research on garment-based "wearables" and biophysical monitoring and a new monitoring method," Studies in Health Technology and Informatics, vol. 108, pp. 111-117, 2004.

[11] P. Düking, M. Tafler, B. Wallmann-Sperlich, B. Sperlich, and S. Kleih, "Behavior change techniques in wrist-worn wearables to promote physical activity: content analysis," JMIR mHealth and uHealth, vol. 8, no. 11, Article ID e20820, 2020.
[12] Y. P. Su and H. S. Wang, "Energy expenditure evaluation of Mt. Qixing Xiaoyoukeng trail: the accuracy of wearable devices," Physical Education Journal, vol. 53, no. 2, pp. 179-187, 2020.

[13] P. Düking, L. Giessing, M. O. Frenkel, K. Koehler, H. C. Holmberg, and B. Sperlich, "Wrist-Worn wearables for monitoring heart rate and energy expenditure while sitting or performing light-to-vigorous physical activity: validation study," JMIR mHealth and uHealth, vol. 8, no. 5, Article ID e16716, 2020.

[14] Y. C. Yang, H. Peng, and L. W. Hsieh, "A study on the effects of road running participation on runners' willingness to purchase wearable sports devices," Taiwan Journal of Sports Scholarly Research, vol. 63, pp. 25-41, 2017.

[15] C. M. Lee and D. H. Lee, "The study of key factors affecting consumers' decisions on purchasing wearable devices using the AHP method," Management Research, vol. 17, pp. 87-123, 2017.

[16] P. Shambrook, P. J. Lander, and O. Maclaren, "A study into the reliability of the data flow from GPS enabled portable fitness devices to the Internet," International Journal of Exercise Science, vol. 11, no. 7, pp. 1184-1193, 2018.

[17] M. J. Tsai and Y. M. Chuang, "Research on personal health status of the master with mobile device," Journal of Data Analysis, vol. 14, no. 5, pp. 39-71, 2019.

[18] Y. J. Chen, C. H. Chang, M. S. Wang, and L. T. Lu, "Effects of exergaming on physical activity: a review of the literature," Chung Yuan Physical Education Journal, vol. 13, pp. 17-27, 2019.

[19] Y. C. Chou and H. J. Lee, "Exploring basketball load in positional difference and training scenario by wearable device," Physical Education Journal, vol. 53, no. 3, pp. 315-326, 2020.

[20] T. H. Davenport and L. Prusak, Working Knowledge: Managing what Your Organization Knows, Harvard Business School Press, Boston, MA, USA, 1988.

[21] C. Lee, Industrial Big Data: Intelligent Transformation and Value Innovation in Industry $4.0 \mathrm{Era}$, Common Wealth Magazine, Taipei, Taiwan, 2016.

[22] C. M. Hsiung, "The application solution for industry 4.0 in Germany, China and taiwan," Journal of the Mechatronic Industry, vol. 406, pp. 20-28, 2017.

[23] H. D. Hsu, "Opinions on occupational safety issues of industry 4.0and coping strategies," Industrial Safety and Hygiene, vol. 379, pp. 32-42, 2021.

[24] Executive Yuan, "Productivity 4.0 initiative of the executive Yuan," 2015, https://www.nchu.edu.tw/ class/bulletin/MOE/ 105_MoE_re_allr.pdf.

[25] H. N. Lee, Y. F. Cheng, C. H. Chang, and J. G. Wu, "Study on attitude toward mobile devices in students with visual impairments: perceived usefulness and perceived ease of use as mediating variables," Bulletin of Educational Psychology, vol. 50, no. 1, pp. 107-129, 2018.

[26] I. Ajzen and M. Fishbein, "A Bayesian analysis of attribution processes," Psychological Bulletin, vol. 82, no. 2, pp. 261-277, 1975.

[27] F. D. Davis, "Perceived usefulness, perceived ease of use, and user acceptance of information technology," MIS Quarterly, vol. 13, no. 3, pp. 319-340, 1989.

[28] S. Y. Chen, Amos Operation of Structural Equation Model, San Ming Book Company Ltd., Taipei, Taiwan, 1st edition, 2007.

[29] W. H. Lee, C. W. Lin, C. W. Lin, and K. H. Shih, "A technology acceptance model for the perception of restaurant service robots for trust, interactivity, and output quality," 
International Journal of Mobile Communications, vol. 16, no. 4, pp. 361-376, 2018.

[30] M. Ismail, E. Çelebi, and H. Nadiri, "How student information system influence students' trust and satisfaction towards the university? An empirical study ina multicultural environment," IEEE Access, vol. 7, 2019.

[31] C. H. Lee, "The technology acceptance of members of public sector for knowledge management," Master's thesis, Institute of Public Affairs Management, National San Yat-sen University, Kaohsiung, Taiwan, 2004.

[32] Y. C. Chang, "A study of elementary school teachers' acceptance of tablet PCs in Yilan County," Master's thesis, Department of Learning and Digital Technology, Fo Guang University, Yilan City, Taiwan, 2012.

[33] D. Sugandini, Purwoko, A. Pambudi, S. Resmi, M. Reniati, and R. A. Kusumawati, "The role of uncertainty, perceived, ease of use, and perceived usefulness toward the technology adoption," International Journal of Civil Engineering \& Technology, vol. 9, no. 4, pp. 660-669, 2018.

[34] C. Y. Lu and C. Y. Lo, "Effects of perceived risk and online banking service experience on mobile banking APP acceptance," Master's thesis, Department of Information Management, Shu-Te University, Kaohsiung City, Taiwan, 2012.

[35] A. N. A. Malik and S. N. S. Annuar, "The effect of perceived usefulness, perceived ease of use, reward, and perceived risk toward E-wallet usage intention," in Eurasian Business and Economics Perspectives, M. H. Bilgin, H. Danis, and E. Demir, Eds., vol. 17, Cham, Switzerland, Springer, 2021.

[36] Y. C. Tsai, The Study of Behavior Intention to Accept the DVD Rental Machine in Technology Acceptance Model, Department of Management Sciences, National Yang Ming Chiao Tung University, Taipei, Taiwan, 2007.

[37] H. Y. Huanh, "Extending the technology acceptance model and flow to explore the intention of mobile games," Master's thesis, Department of Marketing and Distribution Management, National Pingtung University, Pingtung City, Taiwan, 2016.

[38] A. M. Mutahar, N. M. Daud, R. Thurasamy, O. Isaac, and R. Abdulsalam, "The mediating of perceived usefulness and perceived ease of use," International Journal of Technology Diffusion, vol. 9, no. 2, pp. 21-40, 2018.

[39] E. Ünal and A. M. Uzun, "Understanding university students' behavioral intention to use Edmodo through the lens of an extended technology acceptance model," British Journal of Educational Technology, vol. 52, no. 3, 2020.

[40] H. T. Huang, C. Tsai, and D. S. Zhu, "An extension of the motivation model to explore the behavioral intention of health knowledge repository systems: technological-socialmotivational perspectives," Journal of E-Business, vol. 11, no. 3, pp. 569-609, 2009.

[41] R. P. Bagozzi and Y. Yi, "On the evaluation of structure equations models," Academic of Marketing Science, vol. 16, no. 1, pp. 76-94, 1988.

[42] C. Fornell and D. F. Larcker, "Evaluating structural equation models with unobservable variables and measurement error," Journal of Marketing Research, vol. 18, no. 1, pp. 39-50, 1981.

[43] J. F. Hair Jr., R. E. Anderson, R. L. Tatham, and W. C. Black, Multivariate Data Analysis, Prentice-Hall, Englewood Cliffs, NJ, USA, 5th edition, 1998.

[44] G. Torkzadeh, X. Koufteros, and K. Pflughoeft, "Confirmatory analysis of computer self-efficacy," Structural Equation Modeling: A Multidisciplinary Journal, vol. 10, no. 2, pp. 263-275, 2003.
[45] M. W. Browne, R. Cudeck, K. A. Bollen, and J. S. Long, Testing Structural Equation Models, Sage Publications, Thousand Oaks, CA, USA, 1993.

[46] P. M. Bentler, EQS Structural Equations Program Manual, Multivariate Software, Encino, CA, USA, 1995.

[47] G. W. Cheung and R. B. Rensvold, "Evaluating goodness-of-fit indexes for testing measurement invariance," Structural Equation Modeling: A Multidisciplinary Journal, vol. 9, no. 2, pp. 233-255, 2002. 